\title{
Portfólio reflexivo: inovando a forma de ensinar, aprender e avaliar
}

\author{
Ana Paula da Silva Amaral, Rosângela Minardi Mitre Cotta, Erica Toledo de Mendonça, Glauce \\ Dias da Costa, Emily de Souza Ferreira
}

\begin{abstract}
Resumo
Os debates atuais acerca das mudanças necessárias na concepção de ensinar, aprender e avaliar suscitam discussões sobre o uso de métodos ativos de forma a incentivar a participação ativa dos estudantes, tanto no âmbito da (re)construção e aprofundamento como da ampliação dos saberes. Nessa perspectiva, entre os recursos inovadores de ensino, aprendizagem e avaliação, destaca-se o portfólio como instrumento/estratégia de estimulação do pensamento. Especificamente, na Universidade Federal de Viçosa (UFV), na disciplina de Políticas de Saúde, utiliza-se o portfólio reflexivo com o propósito de promover o aprendizado sobre as políticas de saúde, destacando-se a política nacional de saúde no Brasil, o Sistema Único de Saúde (SUS), de forma crítica, reflexiva, dialética e dialógica, visando ao estímulo do trabalho em equipe por meio de um processo de construção coletiva do portfólio. Analisar a percepção de estudantes de graduação em Enfermagem de uma universidade pública sobre o processo de construção do portfólio enquanto estratégia de ensino, aprendizagem e avaliação. Estudo de natureza qualitativa, realizado entre dezembro de 2014 a maio de 2015 com 32 estudantes de Enfermagem que cursaram a disciplina de Políticas de Saúde no segundo semestre de 2014. Os portfólios foram construídos coletivamente por equipes de 6 a 7 alunos e sua avaliação foi contínua e longitudinal, com três avaliações durante o semestre. A coleta de dados foi realizada por meio de entrevista semiestruturada e análise documental dos 7 portfólios construídos coletivamente. Para análise dos dados foi realizada a técnica de Análise do Conteúdo de Lawrence Bardin. O estudo foi aprovado pelo Comitê de Ética em Pesquisa com Seres Humanos da UFV, protocolo ${ }^{\circ}$ 135/2012/ CEPH. Os estudantes identificaram no portfólio um valioso recurso de consolidação do aprendizado; estratégia que estimula o pensamento crítico, reflexivo, criativo; valoriza a participação do estudante na aquisição do conhecimento; embora trabalhoso, permitiu o crescimento enquanto estudante, cidadão e futuro profissional; como avaliação, neste avalia-se para além de um momento e conteúdo pontual, podendo (re)construir, refletir sobre o erro e corrigir rumos. Ademais, o portfólio apresentou-se como facilitador na compreensão dos conteúdos de Políticas de Saúde, fomentador de agentes questionadores - não apenas dos conteúdos da disciplina em si, mas também no contexto de vida e de trabalho. Além de possibilitar aos estudantes uma visão mais ampliada sobre o SUS e potencializar o trabalho em equipe, estimulando o exercício do respeito entre pares, da escuta qualificada e da alteridade. A percepção dos estudantes revelada neste estudo sinalizou que a utilização do portfólio como estratégia de ensino, aprendizagem e avaliação apresentou elementos positivos no que tange ao desenvolvimento de competências, tais como: o trabalho em equipe; o aperfeiçoamento em seu processo de formação profissional e cidadã; a capacitação de futuros profissionais de saúde aptos para o trabalho em equipe; o desenvolvimento da escuta qualificada, a capacidade crítica, reflexiva e argumentativa, o respeito entre pares, a interação, a alteridade e o conhecimento sobre o SUS. Assim, o portfólio mostrou-se como um grande potencial para ampliar, (re)pensar e inovar o ensino de graduação.
\end{abstract}

Descritores: Ensino; Aprendizagem; Avaliação 